\title{
Endometriosis and autoimmunity
}

Noémie Abisror ${ }^{1}$, Kamila Kolanska ${ }^{2,3}$ (1) , Meryem Cheloufi ${ }^{4}$, Lise Selleret ${ }^{2,3}$ () , Emmanuelle d'Argent ${ }^{2,3}$, Gilles Kayem ${ }^{4}$ (), Arsene Mekinian ${ }^{*}{ }^{*}$ (1)

${ }^{1}$ Sorbonne Université, AP-HP, Hôpital Saint-Antoine, service de Médecine Interne and Inflammation-(DMU i3), 75012

Paris, France

${ }^{2}$ Sorbonne Université, AP-HP, Hôpital Tenon, service de Gynécologie-Obstétrique et Médecine de la Reproduction, Université Paris 06, UMRS-938, 75020 Paris, France

${ }^{3}$ GRC-6 Centre Expert En Endométriose (C3E), Sorbonne Université, UMRS-938, 75020 Paris, France

${ }^{4}$ Sorbonne Université, AP-HP, Hôpital Trousseau, service d'Obstétrique, Université Paris 06, 75012 Paris, France

*Correspondence: Arsene Mekinian, Sorbonne Université, AP-HP, Hôpital Saint-Antoine, service de Médecine Interne and Inflammation-(DMU i3), 75012 Paris, France. arsene.mekinian@aphp.fr

Academic Editor: Satish Kumar Gupta, Indian Council of Medical Research, India

Received: August 10, 2021 Accepted: December 13, 2021 Published: February 16, 2022

Cite this article: Abisror N, Kolanska K, Cheloufi M, Selleret L, d'Argent E, Kayem G, et al. Endometriosis and autoimmunity. Explor Immunol. 2022;2:25-31. https://doi.org/10.37349/ei.2022.00034

\begin{abstract}
Endometriosis is an inflammatory oestrogen-dependent chronic disease and is mainly expressed by pain and increased infertility. Several studies showed an increased prevalence of autoimmune systemic diseases and various autoantibodies in endometriosis. The association of these autoimmune markers and diseases could raise the fact that endometriosis is an authentic autoimmune or inflammatory disease and thus could argue for the use of immunomodulatory therapies. Usually, it is considered that the autoantibodies did not directly act in endometrium implants growth, and could be rather implicated in endometriosis-related infertility. The use of immunomodulatory strategies could be an important alternative or additional strategy to the use of hormones and surgery but need prospective well-designed trials.
\end{abstract}

\section{Keywords}

Endometriosis, autoimmune diseases, immunomodulation

\section{Introduction}

Endometriosis is an inflammatory oestrogen-dependent disease characterized by extra-uterine infiltration of endometrial glands and stroma [1]. Endometriosis prevalence is from 5-10\% in women with pelvic pain, dyspareunia, and dysmenorrhea. About $30 \%$ of patients with endometriosis also suffer from infertility [2]. Many women remain asymptomatic, but some of them complain with a variety of symptoms and pain with severe impact on the quality of life and fertility [3]. Endometriosis is a particularly original multifaceted disease, with physiopathological aspects including not only hormonal but also immunological and inflammatory aspects. Different causes could reduce the fertility in endometriosis women, such as adhesions, chronic peritoneal inflammation, disturbed folliculogenesis, and hormonal disturbance. Various immunological

(C) The Author(s) 2022. This is an Open Access article licensed under a Creative Commons Attribution 4.0 International License (https://creativecommons.org/licenses/by/4.0/), which permits unrestricted use, sharing, adaptation, distribution and reproduction in any medium or format, for any purpose, even commercially, as long as you give appropriate credit to the original author(s) and the source, provide a link to the Creative Commons license, and indicate if changes were made. 
factors, such as increased inflammatory factors and immune antibodies mediated disturbances could be also involved in the fertility of endometriosis women. The management actually includes the hormonal therapies (oral contraceptives, progestins, and gonadotropin-releasing hormone agonists), and surgery could be proposed in some refractory cases. These therapies are not sufficient in most cases of endometriosis-related infertility and complementary strategies should be developed.

The frequency of associated autoimmune diseases, of autoantibodies, and the increase of various pro-inflammatory markers should consider the endometriosis as an autoimmune or inflammatory disease. These statements argue for the use of immunomodulatory therapies in the management of endometriosis-related infertility. Despite these arguments, the use of immunomodulation is actually limited in the routine management of endometriosis. Usually, it is considered that autoantibodies do not directly act in endometrium implants growth, which could be rather implicated in endometriosis-related infertility, and represents markers of immune mechanisms. This review aims to describe the prevalence of autoimmune diseases associated with endometriosis, the prevalence of various autoantibodies, and the perspectives of immunomodulatory therapies.

\section{Endometriosis and autoimmune diseases}

The prevalence of several autoimmune diseases is increased in women with endometriosis. Among them, systemic lupus erythematosus (SLE), rheumatoid arthritis (RA), celiac disease, inflammatory bowel disease, Sjogren's syndrome (SS), and autoimmune thyroiditis are particularly involved. A case-control study of 150 women with endometriosis, SLE, celiac disease, inflammatory bowel disease, and autoimmune thyroiditis was more frequent in those with endometriosis [4]. Another case-control study demonstrated an increasing number of immune-mediated conditions and co-occurring endometriosis [5]. A nationwide population-based study showed an increased risk of RA in patients with endometriosis during more than 10-year follow-up [6]. A population-based, retrospective cohort study from Taiwan including endometriosis $(n=16,758)$ and non-endometriosis $(n=16,758)$ women showed a significantly higher incidence rate in women with endometriosis ( 0.3 vs. 0.1 per 1,000 person-years) and hazard ratio (HR) for SLE [adjusted HR (aHR), 2.37; 95\% confidence interval (CI) 1.35-4.14] as compared to the non-endometriosis group [7]. Another retrospective study from Taiwan with a total of 17,779 patients with endometriosis and 17,779 controls without endometriosis showed an increased risk of SLE in those with endometriosis ( 0.85 vs. 0.57 per 1,000 person-years, $\mathrm{HR}=1.86 ; 95 \% \mathrm{CI} 1.36-2.53$ ) as compared to those without endometriosis [8]. In a Swedish study of women with endometriosis from 1964 to 2011, including 2,834 cases of SLE and 14,164 controls, a significant association between endometriosis and subsequent SLE was noted with an odds ratio of 1.39 (95\% CI 1.09-1.78) [9]. Among 114,453 women from the Nurses' Health Study II study followed since 22 years, 103 incident cases of SLE and 390 cases of RA were confirmed and endometriosis was significantly associated with SLE (HR $=2.03$; CI 1.17-3.51) and RA diagnosis (HR $=1.41 ; 95 \% \mathrm{CI}$ 1.05-1.89) [10]. In a case-control study of 58 primary SS (pSS)-patients and 157 controls, endometriosis was reported in $8.5 \%$ of pSS patients vs. $2.1 \%$ of those without pSS [11]. Celiac disease was diagnosed in 5 of $223(2.2 \%)$ women with endometriosis and in 2 of $246(0.8 \%)$ controls $(P=0.265)$ [12]. Among 11,097 women with celiac disease, 118 patients with celiac disease developed endometriosis in comparison with 399 controls without celiac disease among 54,992 age-matched control women [13]. Among 37,661 women with endometriosis from Danish Hospital Discharge Register (1977 to 2007), 13,054 and 86 cases of multiple sclerosis (MS), SLE and SS were noted, respectively, with standardized incidence ratios (SIR) at an odds ratio of 1.2 (95\% CI 1.05-1.5) for MS, odds ratio 1.6 (95\% CI 1.2-2.1) for SLE and odds ratio 1.6 (95\% CI 1.3-2.0) for pSS [14]. When the analysis was restricted to 9,191 women with laparoscopy or laparotomy confirmed endometriosis, associations were significant for MS (SIR = 1.4; 95\% CI 1.04-1.9), but not for SLE (SIR = 1.1; 95\% CI 0.6-2.1) and pSS (SIR = 1.4; 95\% CI 0.9-2.3). Thus, endometriosis could be associated with various autoimmune diseases, even if the force of this demonstration of these associations remains low due to the study biases. 


\section{Autoantibodies in endometriosis}

Various autoantibodies in blood and peritoneal fluids have been studied in endometriosis women, and their prevalence could be increased even in the absence of any autoimmune disease $[15,16]$. The list of autoantibodies that have been detected in endometriosis is very large, and includes antinuclear antibodies (ANAs), antiphospholipids (aPLs), antithyroid, anti-endometrial, anti- $\alpha$-enolase, anti-PDIK1L, anti-survivin, anti-laminin-1, anti-carbonic anhydrase, anti-granulocyte macrophage-colony stimulating factor (anti-GM-CSF) autoantibodies, etc.

For instance, studies showed that anti-endometrial antibodies are more frequent in sera of women with endometriosis and that they are directed against the cytoplasm of glandular and surface epithelium [17]. In women with endometriosis, ANAs, anti-Sjogren's-syndrome-related antigen A (anti-SSA/Ro), and aPL autoantibodies were also more commonly detected usually in the absence of any clinical autoimmune disease [18]. In 323 various stage endometriosis women, anti-cardiolipin antibodies and anti-sperm antibodies were both found to be more frequent in sera and peritoneal fluids [19]. Both levels and prevalence of anti-laminin-1 autoantibodies were increased in endometriosis-associated infertility, but these autoantibodies failed to predict in vitro fertilization (IVF) failure [20,21]. Other rare autoantibodies, such as anti-ovary, anti-theca, anti-granulosa cells, and anti-endometrium autoantibodies have been more frequent in infertile endometriosis women [22]. Among 23 women with endometriosis-associated infertility, aPL except for lupus anticoagulant (LAC), and ANAs were significantly more frequent in women with endometrioses than controls with tubal infertility [23]. Anti-GM-CSF antibodies levels in 106 sera of endometriosis women were increased in patients with endometriosis and with the levels correlated to the severity of the disease [24]. The clinical value and the predictive impact of these various autoantibodies, the correlation of the endometriosis stage, and the value in patients with endometriosis-related infertility remain unclear. Among 35 IVF cycles with at least one aPL or ANA, 8 (23\%) women became pregnant, vs. $16(46 \%)$ in autoantibodies-negative ones $(P=0.04)$ [25]. The levels of anti-alpha enolase antibodies have been found to be increased from stages I to III, but not in stage IV [26]. Anti-PDIK1L and anti-survivin antibodies have not been found to be correlated with the stage of endometriosis [27, 28]. The relevance of these factors thus seems to be limited in clinical practice, and probably reflects more an immunological overall disturbance (Table 1).

Table 1. Immune factors associated with endometriosis-related infertility

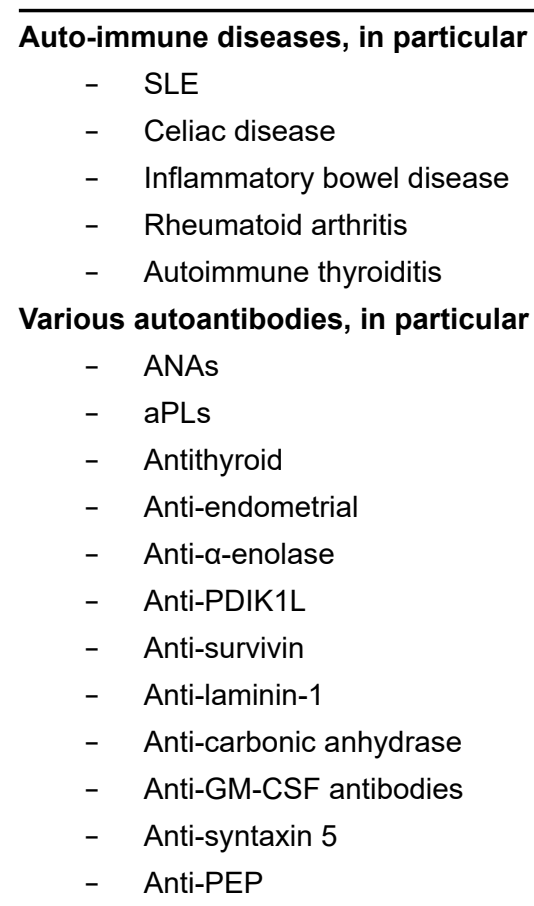

Proinflammatory factors (blood, peritoneum)

anti-PEP: anti-peptide 


\section{Immunomodulatory therapies}

This probable immunological origin of endometriosis, the increased prevalence of various autoimmune biomarkers and autoimmune systemic disorders could raise the interest in immunomodulatory strategies. In particular, in patients with chronic pain resistant to hormonal therapies and surgery, and women with endometriosis-related infertility, alternative strategies are urgently needed. Despite this evidence, the available data about these strategies are extremely scarce.

In a murine embryo assay, the addition of dexamethasone with endometriotic peritoneal fluid significantly improved the rates of blastocyst expansion [29]. Steroids used in 21 patients with endometriosis before IVF, at $10 \mathrm{mg} /$ day from the third day of the cycle until the day of oocyte retrieval [30] allowed an increase of clinical pregnancies rates at $42.6 \%$ in the steroid-treated women vs. $22.8 \%$ without steroids $(P<0.05)$. The clinical pregnancy rates were higher in the steroid-treated group with positive autoantibodies as compared to the non-treated group $(40.9 \% v s .14 .8 \% ; P<0.05)$. In 84 infertile women with endometriosis which received steroids during the IVF cycle or 5 days before embryo transfer, steroid use during the IVF cycle in 35 autoantibodies-positives patients was associated with clinical pregnancy in $8 / 10$ cases vs. $0 / 25$ in those without steroid treatment ( $80 \%$ vs. $0 \% ; P<0.05$ ) [25].

Several studies demonstrated increased levels of pro-inflammatory cytokines, such as tumor necrosis factor- $\alpha$ (TNF- $\alpha$ ), interleukin-6 (IL-6), transforming growth factor- $\beta$ (TGF- $\beta$ ) and IL-1 $\beta$, both in sera and peritoneal fluids of women with endometriosis [31]. In a rat/baboon model of endometriosis, the neutralization of TNF- $\alpha$ activity with recombinant TNF binding protein 1 decreased the endometriotic lesions $[15,16,32-34]$. TNF- $\alpha$ induced peritoneal endometriosis was significantly reduced under anti-TNF- $\alpha$ in endometriosis baboons [35]. Female rats were randomized to receive either etanercept $(0.4 \mathrm{mg} / \mathrm{kg}$ body weight) subcutaneously or placebo once weekly during 4 weeks in a randomized placebo-controlled study using rat endometriosis model [36]. The volume and extension of endometrial implants were significantly reduced in female rats under etanercept. Infliximab is a monoclonal antibody targeting soluble TNF- $\alpha$ and is usually used in several autoimmune and inflammatory diseases, such as RA, Crohn's disease, etc. In a randomized trial of women with endometriosis-related pain, the pain severity decreased in 30\% of infliximab-treated women and was not significantly different from women who received a placebo [37]. Nineteen women with endometrioma received etanercept $50 \mathrm{mg}$ on the second day of the menstrual cycle preceding IVF cycle with higher clinical pregnancy rate in patients who received etanercept: odds ratio 4.17 (95\% CI 1.23-14.14) [38]. In the rat model of endometriosis, a humanized monoclonal antibody against IL-6 receptor, tocilizumab significantly suppressed the volume of endometriotic lesions and the ectopic endometrial-like epithelium: in $42.8 \%$ of treated rats vs. $0 \%$ in the control group [39, 40].

\section{Conclusions}

Endometriosis is associated with an increased prevalence of various autoimmune markers and autoimmune diseases. The use of immunomodulatory strategies could be an important alternative or additional strategy to the use of hormones and surgery but need prospective well-designed trials.

\section{Abbreviations}

ANAs: antinuclear antibodies

anti-GM-CSF: anti-granulocyte macrophage-colony stimulating factor

aPLs: antiphospholipids

CI: confidence interval

HR: hazard ratio

IL-6: interleukin-6

IVF: in vitro fertilization

MS: multiple sclerosis 
pSS: primary Sjogren's syndrome

RA: rheumatoid arthritis

SIR: standardized incidence ratios

SLE: systemic lupus erythematosus

TNF- $\alpha$ : tumor necrosis factor- $\alpha$

\section{Declarations}

\section{Author contributions}

NA, GK and AM contributed conception and design of the study; NA and AM wrote the first draft of the manuscript; KK, MC, LS, EA, GK wrote sections of the manuscript. All authors contributed to manuscript revision, read and approved the submitted version.

\section{Conflicts of interest}

AM is an investigator of CELGENE, ROCHE, CHUGAI founded trials with APHP and Hospital 15-20 promotion; AM received several fees for congress travels and experts' use from LFB, SANOFI, SHIRE, and CELGENE.

\section{Ethical approval}

Not applicable.

\section{Consent to participate}

Not applicable.

\section{Consent to publication}

Not applicable.

\section{Availability of data and materials}

Not applicable.

\section{Funding}

Not applicable.

\section{Copyright}

(c) The Author(s) 2022.

\section{References}

1. Bulun SE. Endometriosis. N Engl J Med. 2009;360:268-79.

2. de Ziegler D, Borghese B, Chapron C. Endometriosis and infertility: pathophysiology and management. Lancet. 2010;376:730-8.

3. Zhang T, De Carolis C, Man GCW, Wang CC. The link between immunity, autoimmunity and endometriosis: a literature update. Autoimmun Rev. 2018;17:945-55.

4. Porpora MG, Scaramuzzino S, Sangiuliano C, Piacenti I, Bonanni V, Piccioni MG, et al. High prevalence of autoimmune diseases in women with endometriosis: a case-control study. Gynecol Endocrinol. 2020;36:356-9.

5. Shafrir AL, Palmor MC, Fourquet J, DiVasta AD, Farland LV, Vitonis AF, et al. Co-occurrence of immune-mediated conditions and endometriosis among adolescents and adult women. Am J Reprod Immunol. 2021;86:e13404.

6. Xue YH, You LT, Ting HF, Chen YW, Sheng ZY, Xie YD, et al. Increased risk of rheumatoid arthritis among patients with endometriosis: a nationwide population-based cohort study. Rheumatology (Oxford). 2021;60:3326-33. 
7. Fan YH, Leong PY, Chiou JY, Wang YH, Ku MH, Wei JC. Association between endometriosis and risk of systemic lupus erythematosus. Sci Rep. 2021;11:532.

8. Lin YH, Yang YC, Chen SF, Hsu CY, Shen YC. Risk of systemic lupus erythematosus in patients with endometriosis: a nationwide population-based cohort study. Arch Gynecol Obstet. 2020;302:1197-203.

9. Harris HR, Simard JF, Arkema EV. Endometriosis and systemic lupus erythematosus: a population-based case-control study. Lupus. 2016;25:1045-9.

10. Harris HR, Costenbader KH, Mu F, Kvaskoff M, Malspeis S, Karlson EW, et al. Endometriosis and the risks of systemic lupus erythematosus and rheumatoid arthritis in the Nurses' Health Study II. Ann Rheum Dis. 2016;75:1279-84.

11. Haga HJ, Gjesdal CG, Irgens LM, Ostensen M. Reproduction and gynaecological manifestations in women with primary Sjögren's syndrome: a case-control study. Scand J Rheumatol. 2005;34:45-8.

12. Santoro L, Campo S, D'Onofrio F, Gallo A, Covino M, Campo V, et al. Looking for celiac disease in Italian women with endometriosis: a case control study. Biomed Res Int. 2014;2014:236821.

13. Stephansson O, Falconer H, Ludvigsson JF. Risk of endometriosis in 11,000 women with celiac disease. Hum Reprod. 2011;26:2896-901.

14. Nielsen NM, Jørgensen KT, Pedersen BV, Rostgaard K, Frisch M. The co-occurrence of endometriosis with multiple sclerosis, systemic lupus erythematosus and Sjogren syndrome. Hum Reprod. 2011;26:1555-9.

15. Greenbaum H, Galper BL, Decter DH, Eisenberg VH. Endometriosis and autoimmunity: can autoantibodies be used as a non-invasive early diagnostic tool? Autoimmun Rev. 2021;20:102795.

16. Tomassetti C, Meuleman C, Pexsters A, Mihalyi A, Kyama C, Simsa P, et al. Endometriosis, recurrent miscarriage and implantation failure: is there an immunological link? Reprod Biomed Online. 2006;13:58-64.

17. Fernández-Shaw S, Hicks BR, Yudkin PL, Kennedy S, Barlow DH, Starkey PM. Anti-endometrial and anti-endothelial auto-antibodies in women with endometriosis. Hum Reprod. 1993;8:310-5.

18. Taylor PV, Maloney MD, Campbell JM, Skerrow SM, Nip MM, Parmar R, et al. Autoreactivity in women with endometriosis. Br J Obstet Gynaecol. 1991;98:680-4.

19. Ulcová-Gallová Z, Bouse V, Svábek L, Turek J, Rokyta Z. Endometriosis in reproductive immunology. Am J Reprod Immunol. 2002;47:269-74.

20. Caccavo D, Pellegrino NM, Totaro I, Vacca MP, Selvaggi L, Depalo R. Anti-laminin-1 antibodies in sera and follicular fluid of women with endometriosis undergoing in vitro fertilization. Int J Immunopathol Pharmacol. 2011;24:481-8.

21. Inagaki J, Hao L, Nakatsuka M, Yasuda T, Hiramatsu Y, Shoenfeld Y, et al. A possible mechanism of autoimmune-mediated infertility in women with endometriosis. Am J Reprod Immunol. 2011;66:90-9.

22. Mathur S, Peress MR, Williamson HO, Youmans CD, Maney SA, Garvin AJ, et al. Autoimmunity to endometrium and ovary in endometriosis. Clin Exp Immunol. 1982;50:259-66.

23. Kaider AS, Kaider BD, Janowicz PB, Roussev RG. Immunodiagnostic evaluation in women with reproductive failure. Am J Reprod Immunol. 1999;42:335-46.

24. Toullec L, Batteux F, Santulli P, Chouzenoux S, Jeljeli M, Belmondo T, et al. High levels of anti-GM-CSF antibodies in deep infiltrating endometriosis. Reprod Sci. 2020;27:211-7.

25. Dmowski WP, Rana N, Michalowska J, Friberg J, Papierniak C, el-Roeiy A. The effect of endometriosis, its stage and activity, and of autoantibodies on in vitro fertilization and embryo transfer success rates. Fertil Steril. 1995;63:555-62.

26. Nabeta M, Abe Y, Kagawa L, Haraguchi R, Kito K, Ueda N, et al. Identification of anti- $\alpha$-enolase autoantibody as a novel serum marker for endometriosis. Proteomics Clin Appl. 2009;3:1201-10.

27. Lamp M, Saare M, Kadastik Ü, Karro H, Salumets A, Uibo R, et al. Survivin promoter polymorphisms and autoantibodies in endometriosis. J Reprod Immunol. 2012;96:95-100. 
28. Nabeta M, Abe Y, Haraguchi R, Kito K, Kusanagi Y, Ito M. Serum anti-PDIK1L autoantibody as a novel marker for endometriosis. Fertil Steril. 2010;94:2552-7.e1.

29. Heitmann RJ, Tobler KJ, Gillette L, Tercero J, Burney RO. Dexamethasone attenuates the embryotoxic effect of endometriotic peritoneal fluid in a murine model. J Assist Reprod Genet. 2015;32:1317-23.

30. Kim CH, Chae HD, Kang BM, Chang YS, Mok JE. The immunotherapy during in vitro fertilization and embryo transfer cycles in infertile patients with endometriosis. J Obstet Gynaecol Res. 1997;23:463-70.

31. Falconer H, Sundqvist J, Gemzell-Danielsson K, von Schoultz B, D'Hooghe TM, Fried G. IVF outcome in women with endometriosis in relation to tumour necrosis factor and anti-Müllerian hormone. Reprod Biomed Online. 2009;18:582-8.

32. Barrier BF, Bates GW, Leland MM, Leach DA, Robinson RD, Propst AM. Efficacy of anti-tumor necrosis factor therapy in the treatment of spontaneous endometriosis in baboons. Fertil Steril. 2004;81:775-9.

33. D’Antonio M, Martelli F, Peano S, Papoian R, Borrelli F. Ability of recombinant human TNF binding protein-1 (r-hTBP-1) to inhibit the development of experimentally-induced endometriosis in rats. J Reprod Immunol. 2000;48:81-98.

34. D'Hooghe TM, Nugent NP, Cuneo S, Chai DC, Deer F, Debrock S, et al. Recombinant human TNFRSF1A (r-hTBP1) inhibits the development of endometriosis in baboons: a prospective, randomized, placebo- and drug-controlled study. Biol Reprod. 2006;74:131-6.

35. Falconer H, Mwenda JM, Chai DC, Wagner C, Song XY, Mihalyi A, et al. Treatment with anti-TNF monoclonal antibody (c5N) reduces the extent of induced endometriosis in the baboon. Hum Reprod. 2006;21:1856-62.

36. Islimye M, Kilic S, Zulfikaroglu E, Topcu O, Zergeroglu S, Batioglu S. Regression of endometrial autografts in a rat model of endometriosis treated with etanercept. Eur J Obstet Gynecol Reprod Biol. 2011;159:184-9.

37. Koninckx PR, Craessaerts M, Timmerman D, Cornillie F, Kennedy S. Anti-TNF-alpha treatment for deep endometriosis-associated pain: a randomized placebo-controlled trial. Hum Reprod. 2008;23:2017-23.

38. Önalan G, Tohma YA, Zeyneloğlu HB. Effect of etanercept on the success of assisted reproductive technology in patients with endometrioma. Gynecol Obstet Invest. 2018;83:358-64.

39. El-Zayadi AA, Mohamed SA, Arafa M, Mohammed SM, Zayed A, Abdelhafez MS, et al. Anti-IL-6 receptor monoclonal antibody as a new treatment of endometriosis. Immunol Res. 2020;68:389-97.

40. Taskin MI, Gungor AC, Adali E, Yay A, Onder GO, Inceboz U. A humanized anti-interleukin 6 receptor monoclonal antibody, tocilizumab, for the treatment of endometriosis in a rat model. Reprod Sci. 2016;23:662-9. 